TITLE:

\title{
Modeling and simulation of spring steel damper based on parameter identification with a heuristic optimization approach
}

\section{$\operatorname{AUTHOR(S):~}$}

Yamakawa, Makoto; Nihei, Mitsuki; Tatibana, Masahiko; Hukazawa, Kyouzou; Ohsaki, Makoto; Nakamura, Takuzo; Yamanouchi, Hiroyuki

\section{CITATION:}

Yamakawa, Makoto ...[et al]. Modeling and simulation of spring steel damper based on parameter identification with a heuristic optimization approach. Journal of Mechanical Science and Technology 2015, 29(4): 1465-1472

ISSUE DATE:

2015-04

URL:

http://hdl.handle.net/2433/217228

\section{RIGHT:}

The final publication is available at Springer via http://dx.doi.org/10.1007/s12206-0150319-3; この論文は出版社版でありません。引用の際には出版社版をご確認ご利用くだ さい。; This is not the published version. Please cite only the published version. 


\title{
Modeling and Simulation of Spring Steel Damper Based on Parameter Identification with a Heuristic Optimization Approach
}

\author{
Makoto Yamakawa ${ }^{1, *}$, Mitsuki Nihei ${ }^{2}$, Masahiko Tatibana ${ }^{1}$, Kyouzou Hukazawa ${ }^{3}$, \\ Makoto Ohsaki ${ }^{4}$, Takuzo Nakamura ${ }^{5}$ and Hiroyuki Yamanouchi ${ }^{1}$ \\ ${ }^{1}$ Department of Architecture, Tokyo Denki University, 120-8551, Tokyo, Japan \\ ${ }^{2}$ TDU Architects, 120-0026, Tokyo, Japan \\ ${ }^{3}$ JARGC Central Research for Construction Technology, 103-0026, Tokyo, Japan \\ ${ }^{4}$ Department of Architecture, Hiroshima University, 739-8527, Higashi-Hiroshima, Japan \\ ${ }^{5}$ NAKAMURA BUSSANN Ltd., 982-0024, Sendai, Japan
}

(Manuscript Received 000 0, 2013; Revised 000 0, 2013; Accepted 000 0, 2013)

\begin{abstract}
In seismic design of building frames, dampers are designed to absorb an earthquake's energy. It is known that conventional steel tension braces have disadvantages; pinching or deterioration of stiffness and strength under cyclic loading. A new type of elasto-plastic damper can potentially avoid such disadvantages at a relatively low cost. Main characteristics of the damper are twofold: i) hardening effect caused by geometric nonlinearity, and ii) asymmetric hysteretic restoring force in tensile and compressive loading conditions. The objectives of the study is to present a constitutive model and identification of the corresponding parameters. We point out that the process of parameter identification of the model is formulated as a non-smooth optimization problem and derivative-free optimization methods are suited for the problem. Through numerical examples, we investigate the seismic response reduction property of the damper. The results demonstrate the effectiveness of the optimization approach.
\end{abstract}

Keywords: Elasto-plastic damper; Hysteresis model; Non-smooth optimization; Parameter identification; Seismic design

\section{Introduction}

Passive dampers such as buckling restrained brace, tuned mass/liquid damper and MR damper are used for seismic design of building frames to absorb the energy during earthquake excitation [1-3]. It is known that conventional steel tension braces have disadvantages such as pinching or deterioration of stiffness and strength under cyclic loading. Co-authors proposed a new type of elasto-plastic damper [4,5]. The dampers are placed in the inter-story as shown in Fig. 1, and it can potentially avoid such pinching or deterioration at a relatively low cost. Main characteristics of the damper are twofold: i) hardening effect caused by geometric nonlinearity, and ii) asymmetric hysteretic restoring force in tensile and compressive loading conditions. This paper about the damper is divided into three parts.

First, we present a constitutive model and identification of the corresponding parameters. In particular, we adopt smooth hysteresis model. Algebraic nonlinear models such as the Ramberg-Osgood model, the Menegotto-Pinto model, etc., exhibit smooth virgin curves and do not violate Drucker's

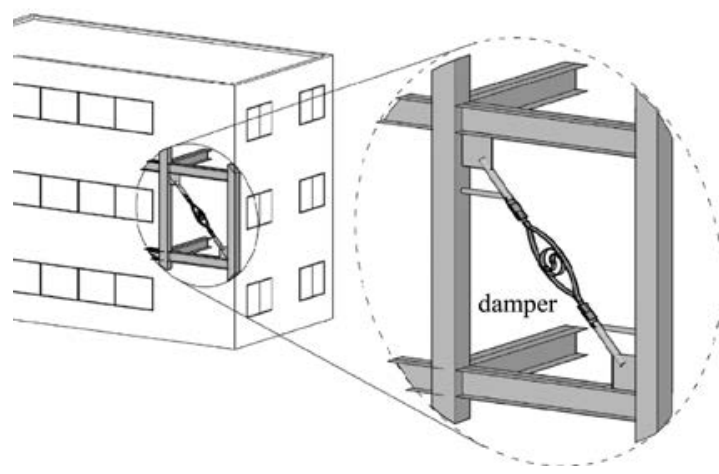

Fig. 1. Proposed damper placed in a building

stability postulate; however, their implementation and/or extensions are not so trivial [6]. Another choice is a plasticity based model, which can avoid such difficulties. We propose an extension of a plasticity based model by Ozdemir [7].

Second, we use a heuristic optimization approach to parameter identification of the proposed model. Several studies have

*Corresponding author. Tel.: +81 35284 5531, Fax.: +81 352845696

E-mail address: myamakawa@mail.dendai.ac.jp

${ }^{\dagger}$ Recommended by Editor 000 000-

(c) KSME \& Springer 2013 
attempted heuristic optimization approaches for parameter identification of constitutive models for various materials [810]. We will discuss different type of damper, material, and numerical method; however, it can be said that this study is also classified in the similar category of the studies.

Finally, we investigate the performance of seismic response reduction by using the identified numerical model. This enables us to show the effectiveness of placing the damper and the heuristic optimization approach.

\section{Experimental test setup and results}

Co-authors conducted quasi-static loading tests of the proposed damper [4,5]. We summarize the test setup and the experimental results. The damper consists of two curved plates of spring steel, and an S-shaped and four C-shaped plates of low-yield-point (LYP) steel as shown in Fig. 2. The spring steel has high-strength compared with the most common steel grades used for building construction. On the other hand, the LYP exhibits lower yield point than the common steel grades, and has excellent elongation and low cycle fatigue characteristics. The material test results are listed in Table 1 . The working mechanism of the damper is illustrated in Fig.3. The damper works even in relatively large deformation because the spring steel remains in elastic state under such large deformation and the LYP steel also shows stable loop, which means effective hysteresis damping. As seen in Fig.3, the damper has asymmetric hysteretic restoring force in tensile and compressive loading conditions due to geometric nonlinearity. Note that the spring steel retains elasticity, so that it behaves like a nonlinear elastic material.

Co-authors performed quasi-static cyclic tests on the system. Figure 4 illustrates the detail of the specimen. The plates of spring steel (width $=80 \mathrm{~mm}$, thickness $=10 \mathrm{~mm}$ ) are curved with $870 \mathrm{~mm}$ radius of curvature, and are connected with friction joints which is tightened by high-tension bolts (diameter $=22 \mathrm{~mm}$ ). The S-shaped plates of LYP (width $=80 \mathrm{~mm}$, thickness $=6 \mathrm{~mm}$ ), the large and the small ones are curved with $59.5 \mathrm{~mm}, 131 \mathrm{~mm}$ and $53.5 \mathrm{~mm}$ radii of curvature, respectively. They are connected by normal bolts (diameter $=14 \mathrm{~mm}$ ).

The specimens were operated in displacement control to apply quasi-static, reversed cyclic loading with incremental displacement amplitudes. The displacement amplitudes are given by 7, 14, 21, 28 and 35mm, which correspond to interstory drift angles of 1/300, 1/150,1/100, 1/75 and 1/60 radian when the dampers are used as diagonal bracing at 45-degree angles for story height of $3 \mathrm{~m}$. Figure 5 shows the relationship between force and elongation obtained from the experiment.
Table 1. Material test results.

\begin{tabular}{ccc}
\hline & Spring steel & Low-yield point steel \\
\hline Grade & SUP9A & LY100 \\
Thickness (mm) & 10 & 6 \\
Yield Strength (MPa) & 1,240 & 111 \\
$\begin{array}{c}\text { Ultimate Tensile } \\
\text { Sttength (MPa) }\end{array}$ & 1,334 & 292 \\
$\begin{array}{c}\text { Percentage elongation } \\
\text { after fracture (\%) }\end{array}$ & 9 & 49 \\
\hline
\end{tabular}

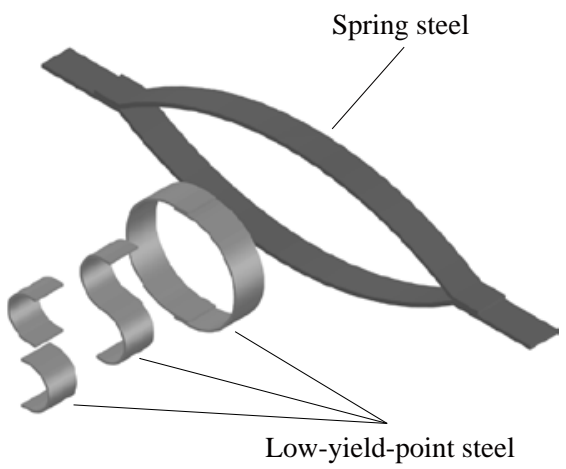

Fig. 2. Components of the proposed damper
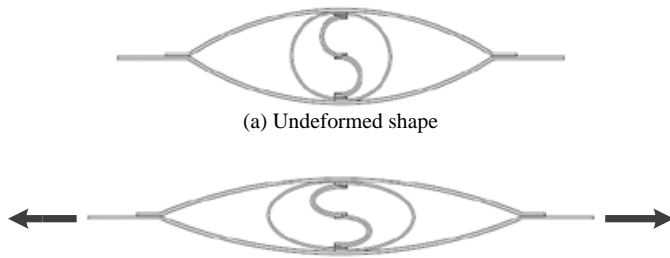

(b) Deformation under uniaxial tension

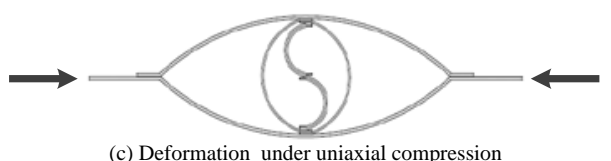

Fig. 3. Working mechanism of the damper

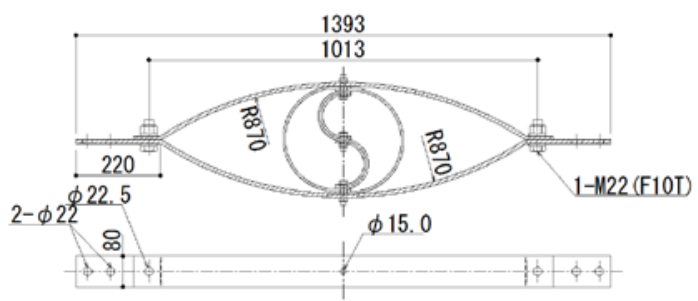

Fig. 4. Detail of the specimen 


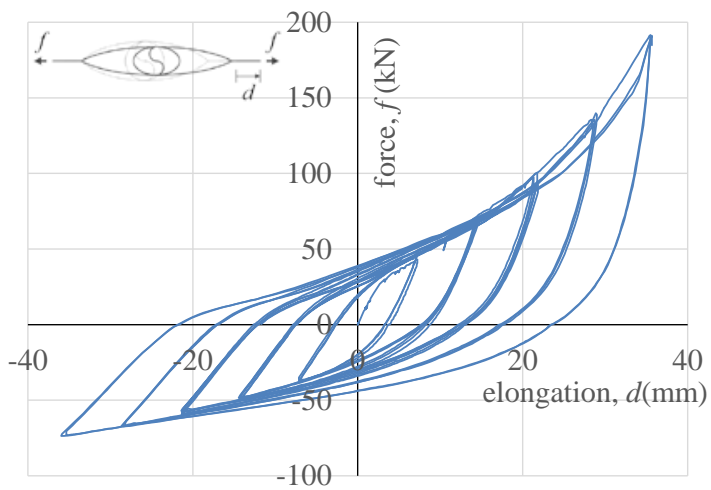

Fig. 5. Result of cycle test: force and elongation relation

\section{Identification of hysteresis model}

In the fields of mechanical engineering, various constitutive models have been developed [6-12]. The material models can be broadly classified into two types, polygonal hysteresis model and smooth hysteresis model. We adopt smooth hysteresis model, which refers to models with continuous change of stiffness due to yielding but sharp change due to unloading behavior. Such models are typically characterized by control parameters. It is also pointed out that parameter identification from observed experimental testing is one of the promising fields of application of optimization methods [10]. We present a new constitutive model for the damper and determine corresponding parameters by a heuristic optimization approach.

\subsection{Ozdemir model}

We summarize the basic Ozdemir model [7] with slightly different notation from the original one but the essentials are the same. Constitutive equation and evolutionary rule of the inelastic strain in uniaxial loading are respectively given by

$$
\begin{aligned}
& \dot{\sigma}=E\left(\dot{\varepsilon}-\dot{\varepsilon}_{\text {in }}\right), \\
& \dot{\varepsilon}_{\text {in }}=|\dot{\varepsilon}| \cdot \operatorname{sgn}(\xi) \cdot|\xi|^{n},
\end{aligned}
$$

where $\sigma$ is the uniaxial stress; $\varepsilon$ is the uniaxial strain; $\varepsilon_{\text {in }}$ is the nonlinear inelastic component; $E$ is the elastic modulus; $\xi$ is the normalized relative stress; $n$ is a constant controlling the sharpness of transition from elastic to plastic states; ( ) denotes ordinary time derivative; and $\operatorname{sgn}(\cdot)$ is the sign function defined as

$$
\operatorname{sgn}(\xi)=\left\{\begin{array}{cc}
+1 & (\xi>0) \\
0 & (\xi=0) \\
-1 & (\xi<0)
\end{array}\right.
$$

Assuming kinematic hardening, normalized relative stress $\xi$ and evolutionary equation of the backstress $\beta$ are respectively defined as

$$
\begin{aligned}
& \xi=(\sigma-\beta) / Y, \\
& \dot{\beta}=\alpha E \dot{\varepsilon}_{\text {in }},
\end{aligned}
$$

where $Y$ is the yield stress; and $\alpha$ is a constant controlling the slope of the $\sigma-\varepsilon$ curve. From Eqs. (1)-(5), it can be seen that the stress-strain behavior is rate-independent.

\subsection{Proposed hysteresis model}

The proposed damper has two main characteristics: i) hardening effect caused by geometric nonlinearity, and ii) asymmetric hysteretic restoring force in tensile and compressive loading conditions. To express such behaviors, we propose an extension of Ozdemir's form. We divide the restoring force into two terms:

$$
F_{D}=F_{D}^{A}+F_{D}^{H}
$$

where $F_{D}, F_{D}^{A}$ and $F_{D}^{H}$ represent the restoring force of the damper, the corresponding asymmetrical force and the corresponding geometric hardening force, respectively.

In the same way as Eqs. (1) and (2), constitutive equation and evolutionary rule of the inelastic component corresponding to asymmetrical force are respectively given by

$$
\begin{aligned}
& \dot{F}_{D}^{A}=K_{D}^{A}\left(\dot{d}-\dot{d}_{\text {in }}\right), \\
& \dot{d}_{\text {in }}=|\dot{d}| \cdot \operatorname{sgn}(\xi) \cdot|\xi|^{n},
\end{aligned}
$$

where $F_{D}^{A}$ is the uniaxial force; $d$ is the uniaxial elongation; $K_{D}^{A}$ is the corresponding elastic stiffness; and $d_{\text {in }}$ is the inelastic component. Normalized relative force $\xi$, evolutionary equation of the backforce $\beta$, the sharpness parameter $n$ are respectively given by

$$
\begin{aligned}
& \xi=\left(F_{D}^{A}-\beta\right) / Y, \\
& \beta=\frac{1}{2}\left\{\left(Y^{+}+\beta^{+}\right)+\left(Y^{-}+\beta^{-}\right)\right\}, \\
& n= \begin{cases}n^{+} & (\dot{d} \geq 0) \\
n^{-} & (\dot{d}<0),\end{cases}
\end{aligned}
$$

with

$$
\begin{aligned}
& \dot{\beta}^{+}=\alpha^{+} K_{D}^{A} \dot{d}_{\text {in }}, \\
& \dot{\beta}^{-}=\alpha^{-} K_{D}^{A} \dot{d}_{\text {in }}, \\
& Y=\frac{1}{2}\left\{\left(Y^{+}+\beta^{+}\right)-\left(Y^{-}+\beta^{-}\right)\right\},
\end{aligned}
$$

where kinematic hardening and axial yield forces are assumed differently in tensile and compressive loading conditions; $(\cdot)^{+}$and $(\cdot)^{-}$correspond to parameters in tensile and compressive loading conditions, respectively; $Y^{(\cdot)}$ are the axial 
yield forces; $\beta^{(\cdot)}$ are the backforces; $n^{(\cdot)}$ are the sharpness parameters; and $\alpha^{(\cdot)}$ are the slope parameters.

The corresponding geometric hardening force is given by

$$
F_{D}^{H}=\frac{K_{D}^{H}}{\eta}\{\exp (\eta d)-1\}
$$

where $K_{D}^{H}$ is the corresponding elastic stiffness and $\eta$ is the scaling (constant) factor of hardening. Obviously the following relation holds:

$$
\dot{F}_{D}^{H}=K_{D}^{H} \exp (\eta d) \dot{d} .
$$

\subsection{Identification of parameters}

For use of the hysteresis model in subsection 3.2, we need a set of parameters:

$$
\theta=\left\{K_{D}^{A}, Y^{+}, Y^{-}, \alpha^{+}, \alpha^{-}, n^{+}, n^{-}, K_{D}^{H}, \eta\right\},
$$

which is to be identified form the experimental test results in section 2. Let $\tilde{F}_{D}\left(t_{i}\right)$ and $F_{D}\left(t_{i} ; \theta\right)$, respectively, denote the restoring force at time $t_{i}$ of the $i$ th step of the experimental quasi-static loading test in section 2 and the force by the hysteresis model in subsection 3.2 depending on parameter set $\theta$. Then we can formulate parameter identification problem as an optimization problem:

$$
\left.\begin{array}{ll}
\text { Find } & \theta \\
\text { that minimizes } & f(\theta):=\sum_{i}\left(F_{D}\left(t_{i} ; \theta\right)-\tilde{F}_{D}\left(t_{i}\right)\right)^{2}
\end{array}\right\}
$$

The objective function $f(\theta)$ corresponds to sum of squared errors, which is non-continuously differentiable function because some functions in Eqs. (7)-(14) are non-continuously differentiable. Hence, solving problem (18) is classified into non-smooth optimization. We attempt to use a heuristic approach based on derivative-free optimization. In particular, we use directional direct search method (DSM), which is known as an effective robust non-smooth optimization method [1315]. Each iteration of the DSM is organized around a search step and a poll step. The search step is optional and we can skip it. On the contrary, the poll step assures global convergence even for non-smooth optimization. The basic algorithm of DSM is stated in Algorithm 1.

The global convergence of Algorithm 1 depends on the behavior of the step size parameter $\Delta_{k}$, which must approach zero; $\Delta_{k} \rightarrow 0$ as $k \rightarrow \infty$. It is known that imposing a forcing function makes it possible to satisfy this condition. For example, the function is given by

$$
\rho\left(\Delta_{k}\right):=10^{-4} \max \left\{1,\left|f\left(\theta_{k}\right)\right|\right\} \Delta_{k}^{2} .
$$

The total set of search directions can be given by $D=\square^{m}$ for simplicity, where $m$ is the dimension of the design variable space. For further details, see Refs. [13-15].

Algorithm 1. Basic directional direct search method (DSM)

Initialization
Choose $\theta_{0}, \Delta_{\max } \geq \Delta_{0}>0,0<\beta_{1}<1 \leq \beta_{2}$.

Let $D$ be a (possibly infinite) total set of search directions.

For $k=0,1,2, \cdots$

Search step: Try to compute a point with $f(\theta)<$ $f\left(\theta_{k}\right)-\rho\left(\Delta_{k}\right)$ by evaluating the function $f$ at a finite number of points. If such a point is found then set $\theta_{k+1} \leftarrow \theta$, declare the iteration and the search step successful, and skip the poll step.

Poll step: Choose a set of search directions $D_{k} \subset D$. Start evaluating $f$ at points $P_{k}=\left\{\theta_{k}+\Delta_{k} \mathbf{d} \mid\right.$ $\left.\mathbf{d} \in D_{k}\right\}$. If a poll point $\theta_{k}+\Delta_{k} \mathbf{d}_{k}$ is found such that $f(\theta)<f\left(\theta_{k}\right)-\rho\left(\Delta_{k} \square \mathbf{d}_{k} \square\right)$ then stop polling, set $\theta_{k+1} \leftarrow \theta_{k}+\Delta_{k} \mathbf{d}_{k}$, and declare the iteration and the poll step successful. Otherwise declare the iteration unsuccessful and set $\theta_{k+1} \leftarrow \theta_{k}$.

Step size parameter update: If the iteration was successful then maintain or increase the step size parameter: $\Delta_{k+1}=\min \left\{\Delta_{\max }, \beta_{2} \Delta_{k}\right\}$. Otherwise decrease the step size parameter: $\Delta_{k+1}=\beta_{1} \Delta_{k}$.

We use the DSM without the search step and the further details about the algorithm is described in [15]. The identified parameter values using units of $\mathrm{kN}$ and $\mathrm{mm}$ are shown in Table 2. The force-elongation relationship of the experimental observation and the numerical approximation are plotted in Fig. 6. Through the comparison of the results, the proposed hysteresis model fits the observed experimental data.

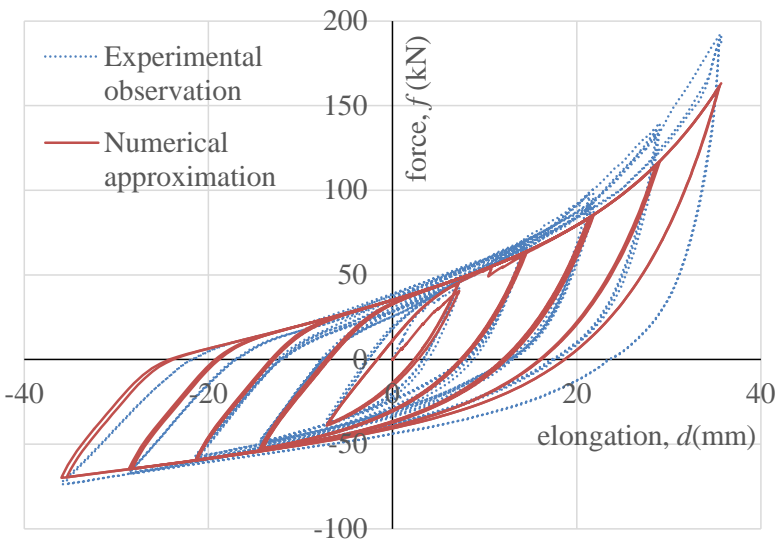

Fig. 6. Comparison of the force-elongation relationships of the experimental observation and the numerical approximation 
Table 2. Identified parameter values (using units of $\mathrm{kN}$ and $\mathrm{mm}$ )

\begin{tabular}{cc|cc}
\hline$K_{D}^{A}(\mathrm{kN} / \mathrm{mm})$ & 6.45 & & \\
$Y^{+}(\mathrm{kN})$ & 47.1 & $Y^{-}(\mathrm{kN})$ & -51.6 \\
$\alpha^{+}$ & 0.25 & $\alpha^{-}$ & 0.11 \\
$n^{+}$ & 2.96 & $n^{-}$ & 1.00 \\
$K_{D}^{H}(\mathrm{kN} / \mathrm{mm})$ & 0.37 & $\eta$ & 0.08 \\
\hline
\end{tabular}

\section{Numerical example}

By using the proposed hysteresis model with the identified parameters, we confirm the seismic response reduction by the damper. This also enables to show the effectiveness of the heuristic optimization approach. It is possible to implement the hysteresis model into a commercial finite element analysis. For example, the ANSYS FEA solver has an open architecture, allowing to write our own subroutines in $\mathrm{C}, \mathrm{C}++$, or FORTRAN and link them to ANSYS as external commands, which are called User Programmable Features (UPFs) [16]. In this study, we do not use such commercial finite element analysis codes but our own code for sake of simplicity.

\subsection{3-story steel building}

Let us consider a 3-story steel building, typical plan and elevation of which are shown in Fig. 7. The steel sections of beams and columns are summarized in Table 3 . The steel material has a bilinear stress-strain relation, where Young's modulus is $E=205 \mathrm{kN} / \mathrm{mm}^{2}$, the kinematic hardening ratio is $0.01 E$ and the yield stress is $235 \mathrm{~N} / \mathrm{mm}^{2}$.

We only consider responses of the structure subjected to seismic motions in the long-span direction, i.e., the damper working direction. Usually, the seismic analysis of buildings is carried out under the assumption that deformation of the diaphragm is negligibly small compared with that of the main lateral load-resisting structure; therefore, the diaphragms can be assumed to be rigid. The rigid diaphragm is a convenient modeling technique for distributing the lateral forces to the frames; forces are distributed to those elements proportionally to their lateral stiffnesses. Thus, we use an equivalent 3-story shear model in the long-span direction as shown in Fig. 8. The inter-story drift angle is given by $\delta_{i}=u_{i} / h_{i}(i=1,2,3)$, where $u_{i}$ is the $i$ th inter-story drift in Fig. 8, and $h_{1}=h_{2}$ $3,250 \mathrm{~mm}$ and $h_{3}=3450 \mathrm{~mm}$ are story heights. The story shear forces of the model are evaluated to the axial forces of the springs placed in the inter-story inFig. 8. The weights of the roof, the 3rd and the 2nd floors are given as $421 \mathrm{kN}$, $597 \mathrm{kN}$ and $769 \mathrm{kN}$, respectively. The relationship between the inter-story drift and the story shear force without the dampers is given as shown in Fig. 9, which approximate the results by pushover analysis of the frame model. The pushover curves of the frame model are also shown in Fig.9.
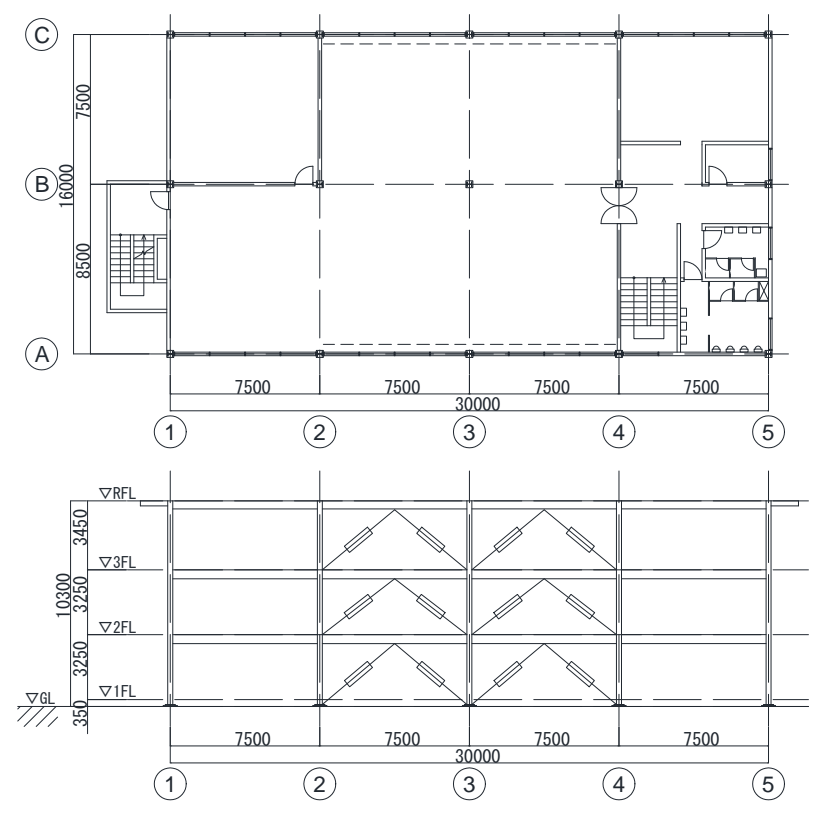

Fig. 7. Typical plan and elevation of a 3-story steel building

Table 3. List of sections

\begin{tabular}{|c|c|}
\hline & Sections \\
\hline Beam (RF) & $H-400 \times 200 \times 8 \times 13$ \\
\hline Beam $(2 F, 3 F)$ & H-450x $200 \times 9 \times 14$ \\
\hline Column & H-250x250×9x14 \\
\hline
\end{tabular}

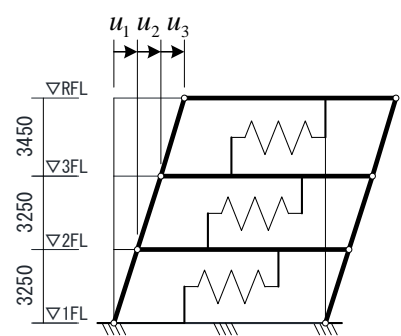

Fig. 8. 3-story shear model

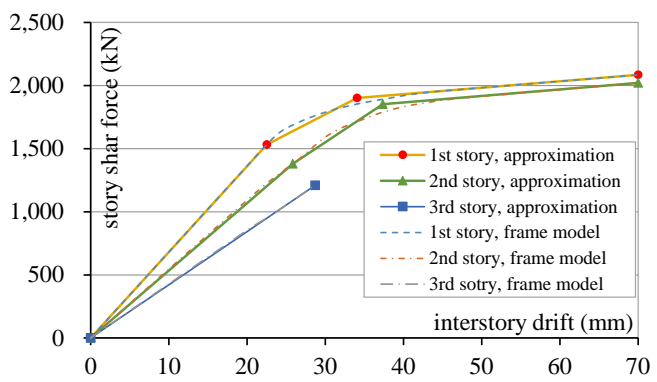

Fig. 9. Relationship between story shear force and inter-story drift of the frame without the dampers 


\subsection{Effectiveness of the damper}

The responses are evaluated by nonlinear transient dynamic analysis. The standard Newmark- $\beta$ method $(\beta=0.25, \gamma=0.5)$ is used for integration in time domain with the increment of $0.01 \mathrm{sec}$. The seismic input is given as shown in Fig. 10, which is the well-known record of earthquake ground motion, El-Centro 1940, N-S component. Peak ground acceleration (PGA) and Peak ground velocity (PGV) of the El-Centro 1940 NS are shown in the row labeled "Case-a" in Table 4. Furthermore, we investigate responses to two other scaled seismic inputs of El-Centro 1940 NS, PGA and PGV of which are designated as "Case-b" and "Case-c" in Table 4.

The force-elongation relations of the single damper in the 1st story are shown in Fig. 11. Through comparison between Figs. 5 and 11, we can see that the proposed hysteresis model with the identified parameters behaves similarly to the experimental results, i.e., the hardening and asymmetric hysteresis.

The responses of the building structure are mainly evaluated by the inter-story drift angle and corresponding story shear force, particularly the maximum values for the duration. The maximum inter-story drift angles in all cases are summarized in Table 5 and reduction ratios of the response are summarized in Table 6, where the ratio is defined as ratio of the maximum inter-story drift angle of the structure by placing the dampers to the corresponding value without the dampers. From Table 6, we can see that the dampers reduce the responses of the structure by between $30 \%$ and $40 \%$ in Case-a and $\mathrm{b}$ from the responses without the dampers. The seismic input in Case-b, scaled to PGV of $50 \mathrm{~cm} / \mathrm{s}$, is extensively used in Japanese design practice as the seismic input level in which limited damage is accepted. On the other hand, the seismic input in Case-c, scaled to more than PGV of $100 \mathrm{~cm} / \mathrm{s}$, is larger than the level used in Japanese design practice. The relationship between story shear force and inter-story drift angle of the 1st story in Case-c with the dampers and without the dampers are shown in Figs. 12 and 13, respectively. It is seen from Figs. 12 and 13 that the stiffness of the frame of the 1st story decreases in large deformation region and the damper supplements the stiffness by geometric hardening. It can be said that the hardening effect of the damper, which can be confirmed in Fig. 11, suppresses deformation concentration of the 1st story.

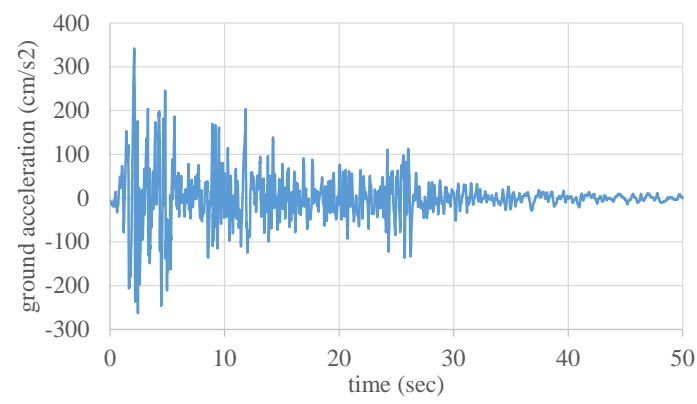

Fig. 10. Seismic input, El-Centro 1940 NS (Case-a)
Table 4. Scale of the seismic input

\begin{tabular}{ccc}
\hline & PGA $\left(\mathrm{cm} / \mathrm{s}^{2}\right)$ & PGV $(\mathrm{cm} / \mathrm{s})$ \\
\hline Case-a & 341.7 & 33.5 \\
Case-b & 509.1 & 50 \\
Case-c & 1171 & 115 \\
\hline
\end{tabular}

Table 5. Maximum inter-story drift angles of the structure $(\times 1 / 1000 \mathrm{rad})$

\begin{tabular}{ccccccc}
\hline & \multicolumn{3}{c}{ Without dampers } & \multicolumn{3}{c}{ With dampers } \\
& Case-a & Case-b & Case-c & Case-a & Case-b & Case-c \\
\hline 3rd story & 2.86 & 4.25 & 7.96 & 1.51 & 2.12 & 4.65 \\
2nd story & 4.80 & 7.12 & 10.59 & 2.79 & 3.98 & 9.05 \\
1st story & $\mathbf{4 . 5 6}$ & $\mathbf{6 . 8 6}$ & $\mathbf{1 6 . 6 7}$ & $\mathbf{3 . 0 5}$ & $\mathbf{4 . 2 3}$ & $\mathbf{1 2 . 4 0}$ \\
\hline
\end{tabular}

Table 6. Reduction ratios of the maximum inter-story drift angles of the structure by the dampers

\begin{tabular}{lccc}
\hline & Case-a & Case-b & Case-c \\
\hline 3rd story & $53 \%$ & $50 \%$ & $58 \%$ \\
2nd story & $58 \%$ & $56 \%$ & $85 \%$ \\
1st story & $67 \%$ & $62 \%$ & $74 \%$ \\
\hline
\end{tabular}

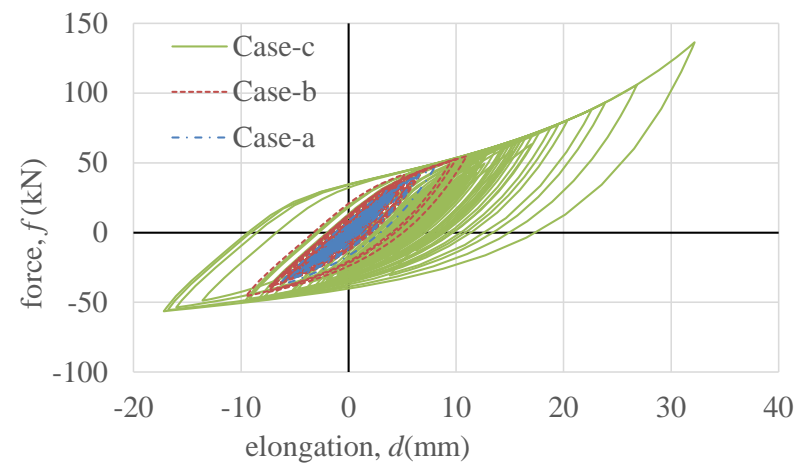

Fig. 11. Responses of the single damper in the 1st story

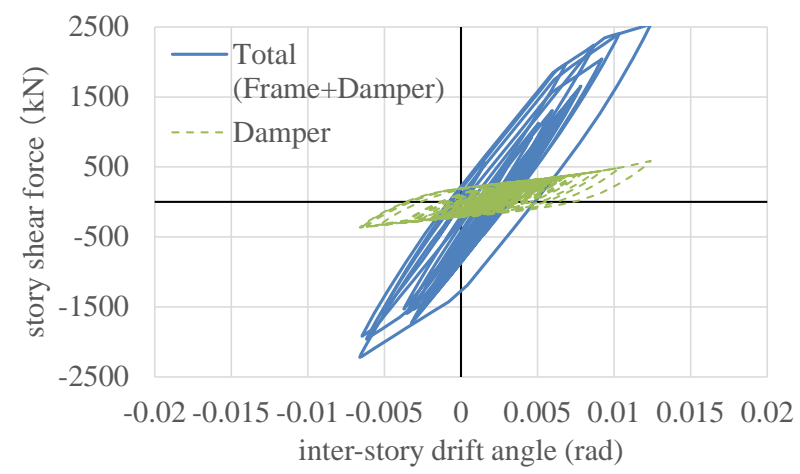

Fig. 12. Response of the 1st story with the dampers in Case-c 


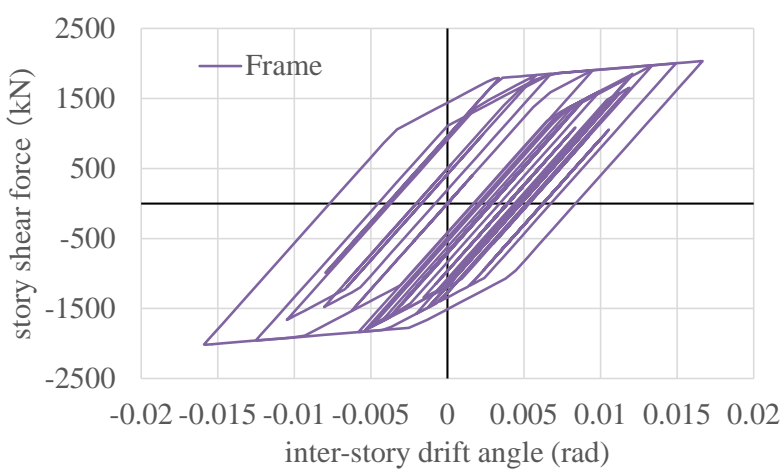

Fig. 13. Response of the 1st story without the damper in Case-c

The results indicate the effectiveness of the heuristic optimization approach for identification of hysteresis model. Parameters may be approximately identified based on preliminary and/or background knowledge if behavior of the damper is known. However, we do not have such knowledge in many cases, e.g., modeling of new material, new structural system and known but complex phenomenon. The heuristic optimization approach can serve as a useful framework even in such difficult situations.

\subsection{Comparison with a conventional damper}

For comparison with a conventional damper, we also use the damper without hardening effect, where the parameters $a^{+}=a^{-}=K_{D}^{H}=0$ are given and the others are same as in Table 2, which can be regarded as the conventional damper, see e.g., Ref. [12]. Typical force-elongation relationship of the conventional damper is denoted as "Without hardening" in Fig. 15 , which behaves like the perfectly elasto-plastic hysteresis. With a focus on the large seismic inputs, we use the one of "Case-c" in previous subsection and JMA-KOBE 1995 NS scaled up 1.3 times, which is referred to as "Case-d". The seismic input of Case-d is given as shown in Fig. 14. The PGA and PGV of the seismic inputs are summarized in Table 7 with Case-c already defined in Table 4.

The maximum inter-story drift angles of the structure in Case-c and Case-d with/without hardening effect are summarized in Table 8. The force-elongation relations of the single damper in the 1st story and the relationship between story shear force and inter-story drift angle of the 1st story are shown in Fig. 15 and Fig. 16, respectively. From Table 8, the maximum response of structure with proposed dampers in Case-d is reduced by $13 \%$ compared to that with the conventional dampers in Case-d, which are indicated in bold font in Table 8. In Fig. 15, the proposed damper with hardening works like stopper and prevents excessive deformation. It is known that JMA-KOBE has the impulsive character. This implies that the proposed damper can be effective to the large impulsive seismic inputs.
Table 7. The large seismic inputs

\begin{tabular}{ccc}
\hline & PGA $\left(\mathrm{cm} / \mathrm{s}^{2}\right)$ & PGV $(\mathrm{cm} / \mathrm{s})$ \\
\hline Case-c & 1171 & 115 \\
Case-d & 1063 & 118.3 \\
\hline
\end{tabular}

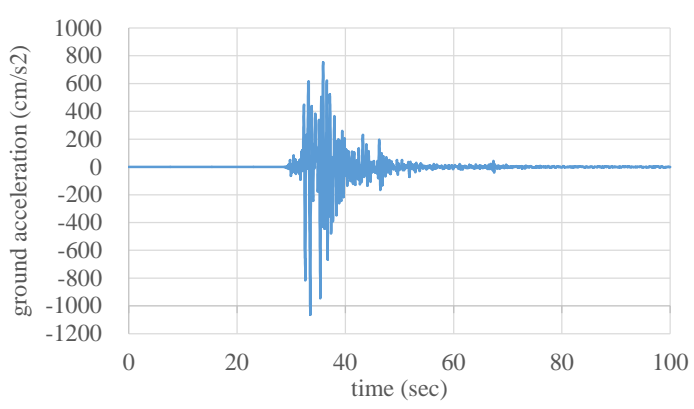

Fig. 14. Seismic input, scaled JMA-KOBE 1995 NS (Case-d)

Table 8. Maximum inter-story drift angles of the structure $(\times 1 / 1000 \mathrm{rad})$

\begin{tabular}{ccccc}
\hline & \multicolumn{2}{c}{ Without hardening } & \multicolumn{2}{c}{ With hardening } \\
& Case-c & Case-d & Case-c & Case-d \\
\hline 3rd story & 4.48 & 4.51 & 4.65 & 5.30 \\
2nd story & 9.30 & 10.15 & 9.05 & 10.26 \\
1st story & 12.67 & $\mathbf{1 8 . 0 3}$ & 12.40 & $\mathbf{1 5 . 6 0}$ \\
\hline
\end{tabular}

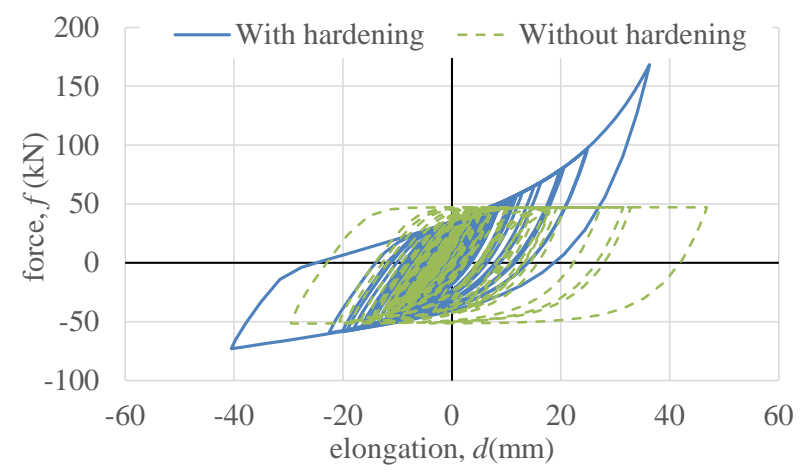

Fig. 15. Responses of the single damper in the 1st story

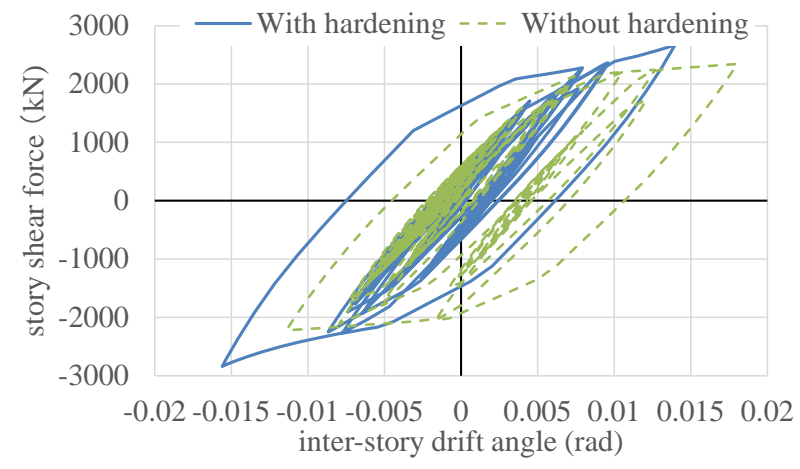

Fig. 16. Responses of the 1st story 


\section{Conclusions}

The conclusions drawn from this study are as follows:

1. We proposed extensions of a hysteresis model by Ozdemir to express hardening effect and asymmetric hysteresis in tensile and compressive loading conditions. The proposed model inherits smooth hysteresis and easy implementation.

2. We pointed out that the identification of the model parameters is classified into a non-smooth optimization problem including non-continuously differentiable functions. Therefore, derivative-free optimization methods are suitable for solving the identification problem.

3. Through a numerical example, we confirmed that the proposed hysteresis model with the identified parameters can accurately simulate the experimentally observed forceelongation relationship in the range of the quasi-static experimental data.

4. Placing the dampers reduces the maximum inter-story drift angle of the structure by between $30 \%$ and $40 \%$ under the seismic input scaled to PGV of $50 \mathrm{~cm} / \mathrm{s}$, and suppresses deformation concentration in the 1st story under the seismic input scaled to PGV of more than $100 \mathrm{~cm} / \mathrm{s}$.

5. Numerical results imply that the proposed damper is effective against the large impulsive seismic inputs compared to a conventional damper that has a perfectly elasto-plastic hysteresis.

\section{Acknowledgment}

We appreciate the provision of data by Mr. Takayuki Matsutsuka, a graduate of Tokyo Denki University. Part of this work was supported by JSPS KAKENHI Grant Number 25420576. We gratefully acknowledge the supports.

\section{References}

[1] Y.M. Kim, K.P. You, J.E. Cho and D.P. Hong, The vibration performance experiment of Tuned Liquid damper and Tuned Liquid Column damper, Journal of Mechanical Science and Technology, 20 (6) (2006) 795-805.

[2] K.M. Choi, H.J. Jung, S.W. Cho and I.W. Lee, Application of smart passive damping system using MR damper to highway bridge structure, Journal of Mechanical Science and Technology, 21 (6) (2007) 870-874.

[3] S.K. Lee, E.C. Park, K.W. Min, S.H. Lee and J.H. Park, Experimental implementation of a building structure with a tuned liquid column damper based on the real-time hybrid testing method, Journal of Mechanical Science and Technology, 21 (6) (2007) 885-890.

[4] S. Kurashima, et al., Experimental study on hysteretic damper consisting spring steel and low yield strength steel: Part 1 Outline of Study, Summaries of Technical Papers of Annual Meeting, Architectural Institute of Japan (2012) 887-888 (In Japanese).

[5] T. Matsutsuka, et al., Experimental study on hysteretic damper consisting spring steel and low yield strength steel:
Part 2 Result of LoadingTest, Summaries of Technical Papers of Annual Meeting, Architectural Institute of Japan (2012) 889-890 (In Japanese).

[6] M.V. Sivaselvan and A. M. Reinhorn, Hysteretic models for deteriorating inelastic structures. Journal of Engineering Mechanics, 126 (6) (2000) 633-640.

[7] H. Ozdemir, Nonlinear transient dynamic analysis of yielding structures. PhD Thesis, University of California, Berkeley (1976).

[8] S. Talatahari, A. Kaveh and N.M. Rahbari, Parameter identification of Bouc-Wen model for MR fluid dampers using adaptive charged system search optimization, Journal of Mechanical Science and Technology, 26 (8) (2012) 25232534.

[9] D.H. Lee, and W.S. Hwang, An identification method for joint structural parameters using an FRF-based substructuring method and an optimization technique, Journal of Mechanical Science and Technology, 21 (12) (2007) 2011-2022.

[10]M. Ohsaki, J.Y. Zhang, and T. Miyamura, A heuristic algorithm for parameter identification of steel materials under asymmetric cyclic elastoplastic deformation, Proc. of 7 th China-Japan-Korea Joint Symposium on Optimization of Structural and Mechanical Systems, Huangshan, China, Paper No. J045 (2012).

[11]J.L. Chaboche, A review of some plasticity and viscoplasticity constitutive theories, Int. J. Plasticity, 24 (2008) 16421693.

[12]Y. Araki, N. Maekawa, K.C. Shrestha, M. Yamakawa, Y. Koetaka, T. Omori and R. Kainuma, Feasibility of tension braces using $\mathrm{Cu}-\mathrm{Al}-\mathrm{Mn}$ superelastic alloy bars, Structural Control and Health Monitoring (2014) DOI: 10.1002/stc. 1644.

[13]C. Audet and J.E. Dennis, Mesh Adaptive direct search algorithms for constrained optimization, SIAM J. Optim., 17 (2006) 188-217.

[14]A.R. Conn, K. Scheinberg, and L.N. Vicente, Introduction to derivative-free optimization, SIAM, Philadelphia (2009).

[15]M, Yamakawa and F. van Keulen, Derivative-free optimization reflecting the geometry of constraints for nonsmooth dynamic responses, Proc. of 9th World Congress on Structural and Multidisciplinary Optimization, Shizuoka, Japan, Paper No. 106_1 (2011).

[16]ANSYS Mechanical APDL programmer's reference, SAS IP, Inc. (2013).

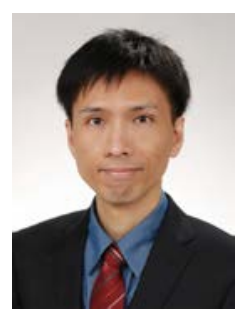

Makoto Yamakawa is an associate professor of School of Science and Technology for Future Life in Tokyo Denki University. He received his Dr. Eng. from Kyoto University. His general research interests include structural optimization, seismic design of buildings and non-linear analysis of spatial structures. 